\title{
Pour en lire plus : « Telling our stories »,
}

Pascal Galvani

\section{OpenEdition}

Journals

Édition électronique

URL : http://journals.openedition.org/ere/5558

DOI : $10.4000 /$ ere. 5558

ISSN : 2561-2271

Éditeur

Centr'ERE

Référence électronique

Pascal Galvani, « Pour en lire plus : "Telling our stories », », Éducation relative à l'environnement [En ligne], Volume 4 | 2003, mis en ligne le 14 septembre 2003, consulté le 24 septembre 2020. URL : http://journals.openedition.org/ere/5558 ; DOI : https://doi.org/10.4000/ere.5558

Ce document a été généré automatiquement le 24 septembre 2020. 


\section{Pour en lire plus : « Telling our stories ",}

\section{Pascal Galvani}

\section{RÉFÉRENCE}

«Telling our stories », Canadian Journal of Environmental Education, Volume 7, numéro 2, 2002.

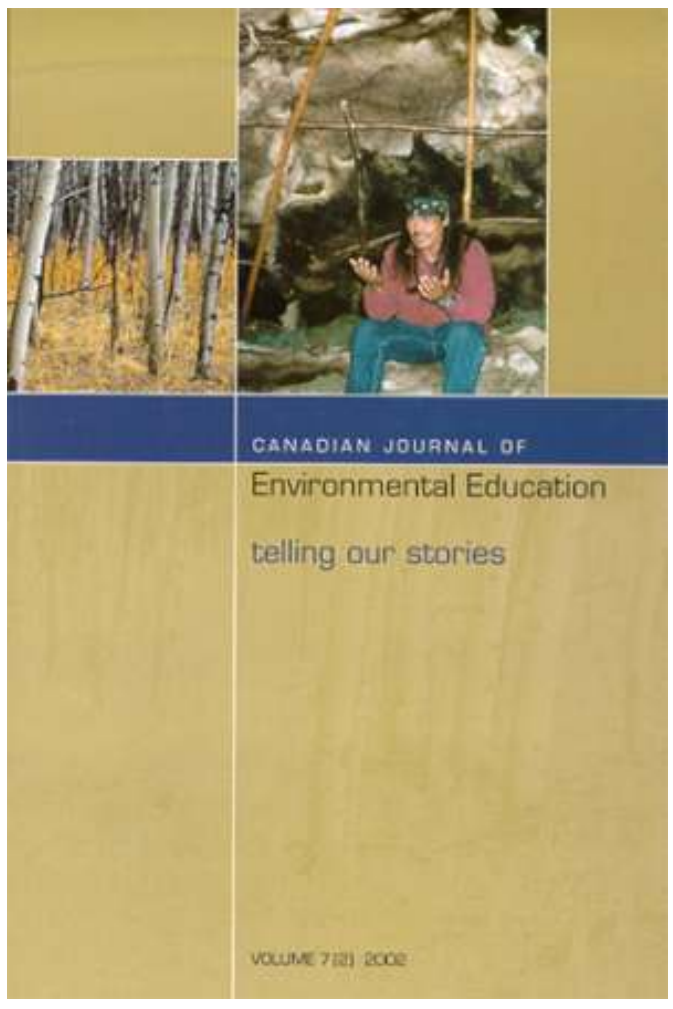


1 Sous le titre "Telling our stories", ce deuxième numéro du volume 7 du Canadian Journal of Environmental Education (CJEE) présente les actes du colloque annuel du Canadian Network for Environmental Education and Communication qui s'est tenu à l'été 2001 à Whitehorse, Yukon. Ce colloque voulait faire une large place aux cultures autochtones des territoires du Nord en travaillant sur le rôle fondamental des mythes et des récits dans l'éducation traditionnelle et dans l'équilibre écosystémique des sociétés et du territoire. Le premier numéro du volume 7 s'interrogeait déjà sur la dimension culturelle des questions environnementales donnant la parole à des intervenants issus de cultures autochtones. Ce type d'initiative est rare et difficile. Les critères académiques et éditoriaux empêchent d'intégrer toutes les contributions dans la publication (Agyeman, 2002).

2 Le projet annoncé par le titre décline une perspective anthropo-cosmique d'une grande ampleur à propos de l'éducation relative à l'environnement. Ici le terme staries veut rendre compte du rôle fondamental des récits et de la narration dans la connaissance et dans les pratiques d'éducation relative à l'environnement. Les histoires sont des mythologies au sens anthropologique de récits qui organisent le sens de toutes les collectivités humaines. Selon l'éditorial de Bob Jickling (2002), les histoires dont nous sommes porteurs «structurent nos perceptions du monde, et même plus que cela, notre être au monde » (traduction libre).

3 Un premier constat émerge : les histoires autochtones révèlent une représentation et un «être au monde» de type relationnel. Pour les auteurs non-autochtones, c'est l'apport fondamental des cultures autochtones aux programmes d'éducation à l'environnement. Dans les histoires amérindiennes, les êtres humains, les éléments cosmiques, les animaux, les plantes, les idées et les rêves sont des histoires avec lesquelles notre propre histoire entre en dialogue. Le philosophe Martin Buber (1969) avait magistralement décrit cette perspective dialogique comme étant celle du " Je-Tu » où la conscience entre en résonance avec les autres et les choses dans un dialogue

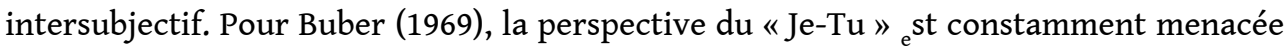
par la perspective du «Je-Cela» où la conscience perçoit tous les êtres comme des objets dotés de caractéristiques dans un rapport d'extériorité et d'objectivation de soi, des autres et des choses. Rappelons ici ce texte d'un philosophe du début du vingtième siècle, c'est dire que ce mode de relation au monde n'est pas exclusivement amérindien même s'il est, à l'évidence, plus valorisé dans les cultures autochtones qu'il ne l'est dans la culture technico-économique occidentale. En partageant leurs histoires respectives, les auteurs autochtones et non-autochtones de ce volume entrent dans un dialogue transculturel et transpersonnel où les visions se révèlent mutuellement dans leurs résonances.

4 Selon l'article d'ouverture du linguiste Robert Bringhurst (2002), les histoires autochtones ouvrent une réalité encore plus déroutante. Dans les cultures autochtones, la littérature n'est pas un phénomène exclusivement humain! Les animaux, les plantes, les paysages sont aussi des histoires comme nous sommes nous-mêmes des histoires. C'est d'ailleurs cela qui fonde la perspective «écologique» des cultures autochtones. Elles orientent «l'être au monde » vers le dialogue. Entrer en dialogue, c'est d'abord écouter, c'est porter une attention silencieuse à ce que le monde et les choses «nous racontent». C'est passer d'un rapport d'usage à un rapport du sage (Pineau, 1991). Raconter et partager nos histoires c'est se donner les moyens d'explorer l'écologie des 
relations entre nos esprits, nos cultures et nos territoires. Partager nos histoires c'est se donner les moyens d'explorer, de former et de transformer ces relations.

Les différentes contributions du volume sont organisées en trois parties. La première partie «Telling stories " rassemble les contributions épistémologiques évoquant les relations entre les histoires, les récits, la terre et la connaissance. En prenant conscience que toute connaissance émerge dans et par des récits, plusieurs auteurs appellent à une réévaluation épistémologique qui réintègre les récits scientifiques et pédagogiques à l'intérieur des histoires et des mythologies culturelles. La seconde partie « What stories tell » rassemble les questions méthodologiques rencontrées dans différentes recherches ayant utilisé les récits et la narration comme démarche centrale. Les auteurs et auteures insistent sur les interactions constantes entre les perspectives culturelles et scientifiques que les récits permettent de conscientiser et d'équilibrer dans les enjeux de transformation sociale que tente de relever l'éducation relative à l'environnement. La troisième section intitulée «Doing stories» rassemble les contributions traitant directement de pratiques d'éducation relative à l'environnement. Deux thèmes traversent ces contributions. Le premier concerne la nécessité de pratiquer une éducation «hors les murs ». Les dimensions expérientielles de la marche, de la vie en plein air, sont ici reprises tant au sens littéral que métaphorique. L'éducation à l'environnement est un "art nomade» et rebelle. La marche est une pédagogie anthropologique dont le paradoxe fondamental est qu'en sortant "à l'extérieur » on rejoint aussi son « intérieur " (Sheridan, 2002). Le second thème est celui de l'équilibre et de la complémentarité des approches objectives, phénoménologiques, expérimentales, poétiques et artistiques dans les pratiques d'éducation relative à l'environnement. On peut regretter que l'objectif initial de faire une place aux savoirs autochtones ne soit pas traité explicitement dans cette partie.

6 À ceux et celles qui souhaitent faire une place aux récits et aux enseignements traditionnels dans les démarches d'éducation relative à l'environnement, on conseillera de se reporter à l'excellent article de Leanne Simpson (2002) dans le numéro précédent de la revue. Universitaire de descendance Anishinaabeg, Leanne Simpson développe les conditions nécessaires à ce type de projet :

- fonder les actions d'éducation à l'environnement en milieu autochtone sur les savoirs autochtones;

- inclure les aînés et les enseignants traditionnels en tant qu'experts ;

- enraciner les programme $e_{s}$ dans la philosophie de l'éducation autochtone ;

- utiliser les modes d'enseignement autochtones;

- connecter les programmes au territoire;

- faire de la place et soutenir la décolonisation dans ses dimensions historiques et contemporaines ;

- inclure la connaissance scientifique occidentale en tant qu'outil au service des valeurs autochtones;

- se tourner vers les anciens pour préparer le futur. 


\section{BIBLIOGRAPHIE}

Agyeman, J. (2002). Guest Editorial - Culturing Environmental Education : From First Nation to Frustration. Canadian Journal of Environmental Education, 7(1), 5-12.

Bringhurst, R. (2002). The Tree of Meaning and the Work of Ecological Linguistics. Canadian Journal of Environmental Education, 7(2), 9-22.

Buber, M. (1969). Je et Tu. Paris : Aubier Montaigne,

Jiciding, B. (2002). Éditorial Telling Our Stories. Canadian Journal of Environmental Education, 7(2), 5-7.

Pineau, G. (1991). Formation expérientielle et théorie tripolaire de la formation. Dans B. Courtois et G. Pineau (dir.), La formation expérientielle des adultes. Paris : La Documentation Française, p. 29-40.

Sheridan, J. (2002). My Name is Walker : An Environmental Resistance Exodus. Canadian Journal of Environmental Education, 7(2), 193-206.

Simpson, L. (2002). Indigenous Environmental Education for Cultural Survival. Canadian Journal of Environmental Education, 7(1), 13-25.

\section{AUTEUR}

\section{PASCAL GALVANI}

Professeur en psychosociologie, Université du Québec à Rimouski 